\title{
DIREITO À SAÚDE NO BRASIL: PARÂMETROS NORMATIVOS PARA DENSIFICAÇÃO DE UM CONTEÚDO MÍNIMO
}

\author{
RIGHT TO HEALTH IN BRAZIL: NORMATIVE PARAMETERS FOR DENSIFICATION OF A MINIMUM \\ CORE
}

Luiz Antônio Freitas de Almeida ${ }^{1}$

\begin{abstract}
Resumo: A judicialização do direito à saúde é um fenômeno crescente no Brasil. Os casos difíceis versam sobre medicamentos e tratamentos não incluídos nas políticas do sistema único de saúde - SUS, tema que foi enfrentado pelo Supremo Tribunal Federal no Recurso Extraordinário n. 566.471/RN. A resposta judicial ineludivelmente perpassará por uma ponderação, que deve passar pela estrutura analítica da norma da proporcionalidade e seus testes. Contudo, para uma maior racionalidade jurídica advinda da maior objetivação da ponderação, é importante acrescentar o conteúdo mínimo como padrão que define o grau de deferência e o ônus de argumentação do Estado. Nessa linha de pensamento, com o uso do método técnico-jurídico, o artigo oferece os parâmetros normativos para auxiliar na definição do conteúdo mínimo do direito à saúde no Brasil. Antes, porém, será preciso verificar a compreensão de conteúdo mínimo dada pelo Comitê de Direitos Econômicos, Sociais e Culturais da Organização das Nações Unidas.
\end{abstract}

Palavras-chave: Direito à saúde. Judicialização. Proporcionalidade. Conteúdo mínimo.

\begin{abstract}
The judicialization of the right to health is a growing phenomenon in Brazil. The hard cases deal with medicaments and treatments not included in public policies of Brazilian's health system, subject that was adressed by Brazilian Supreme Court in "Recurso Extraordinário" n. 566.471/RN. The judicial answer will be constructed by balancing, which demands an analytical structure offered by proportionality and its tests. However, for further legal rationality achieved by further objectification of the balancing, it is important to include the minimum core - standard that defines the intensity of deference and State's argumentative onus. In this line, using the technical-legal method, the article offers the normative patterns that helps in the definition of the minimum core of right to health in Brazil. Before this, notwithstanding, it will be necessary to examine the comprehension of the minimum core professed by United Nations' Committee on Economic, Social, and Cultural Rights.
\end{abstract}

Keywords: Right to health. Judicialization. Proportionality. Minimum core.

Recebido em 18 de outubro de 2018 Avaliado em 29 de abril de 2020 (AVALIADOR A) Avaliado em 30 de abril de 2020 (AVALIADOR B) Aceito em 30 de abril de 2020

\section{Introdução}

Não é de hoje que os reflexos da judicialização da saúde, sobretudo no aspecto de incremento da despesa orçamentária, ${ }^{2}$ são reverberados pelos críticos. Na audiência pública realizada

\footnotetext{
1 Doutor em Ciências Jurídico-Políticas pela Universidade de Lisboa, Portugal; Promotor de Justiça no Mato Grosso do Sul; Rua Luís Freire Benchetrit, 160, Miguel Couto, Campo Grande, Mato Grosso do Sul, Brasil; https://orcid.org/0000-00030584-8417; lafalmeida12@gmail.com

2 Conforme dados divulgados sobre a judicialização da saúde no Brasil no relatório analítico-propositivo do Instituto de Ensino e Pesquisa - Insper (AZEVEDO et al., 2019, p. 13), houve um acréscimo de demandas relativas à saúde em 130\% entre 2008 e 2017, muito superior ao número de crescimento de processos judiciais em geral (50\%). Por outro lado, apenas
} 
pelo Supremo Tribunal Federal em 2009, porém, abriu-se uma divergência sobre qual a ênfase do fenômeno que ocorre no Brasil, isto é, se há em maior intensidade uma judicialização que se limita a reclamar medicamentos e serviços de saúde já incorporados em políticas públicas do Sistema Único de Saúde - SUS ou se, ao revés, o foco maior alcança demandas que pleiteiam ações sanitárias e medicamentos não incorporados nas políticas públicas. ${ }^{3}$

Em realidade, as ações judiciais que se limitam a demandar ações de saúde contidas no catálogo sanitário do SUS não trazem uma problematização jurídico-constitucional de difícil resposta, pois, nesse caso, além das normas dos direitos fundamentais, há incidência das normas concretizadoras desses direitos fundamentais positivadas infraconstitucionalmente e de toda a racionalidade de Direito Administrativo: o cânone da legalidade não deixa sequela de dúvida de que o bem da vida deve ser prestado, mormente porque se amolda ao conceito de integralidade previsto no artigo 19-M da Lei n. 8.080/90 (BRASIL, 1990).

Os "casos difíceis" (DWORKIN, 2007, p. 127-131), no entanto, lidam justamente com medicamentos não registrados na Agência Nacional de Vigilância Sanitária - ANVISA e com medicamentos e serviços não regulados no SUS. O Supremo Tribunal Federal enfrentou as duas questões nos Recursos Extraordinários n. 657.718/MG e n. 566.471/RN, respectivamente. ${ }^{4}$ Como

no orçamento do Ministério da Saúde, em sete anos o custo desembolsado em consequência de decisões judiciais aumentou treze vezes, alcançando o total de R \$ 1,6 bilhão em 2016.

3 Brasil (2009). Conferir p. 45-49, discurso de Dias Toffoli; p. 94-97, discurso de Antônio Nardi; p. 103-106, discurso de Agnaldo Gomes da Costa; p. 106-112, discurso de Rodrigo Mascarenhas; p. 171-175, discurso de Cleusa Bernardo; p. 209214, discurso de Paulo Picon; p. 219-223, discurso de Janaína Gonçalves, todos a sustentar que a ênfase na judicialização da saúde é para reclamar prestações não incluídas nas políticas públicas. Em diapasão contrário, aduzindo que a grande parte das ações judiciais de saúde demanda prestações já previstas em leis e nas políticas públicas, os discursos de Ingo Sarlet, p. 76; de Cláudia Fernanda de Oliveira Pereira, p. 140; e de Gisele Martins Vergara, p. 144-148.

4 O Superior Tribunal de Justiça, no julgamento do Recurso Especial n. 1.657.156 (BRASIL, 2017a), julgado como recurso repetitivo, também enfrentou a questão de medicamentos não incorporados nas políticas públicas do SUS. A Corte Superior fixou a tese de que é possível o fornecimento de medicamentos, desde que cumulados os seguintes requisitos: i) comprovação da necessidade sanitária do demandante e da ineficácia daqueles previstos nas políticas públicas por laudo médico; ii) incapacidade financeira de arcar com seus custos; iii) existência de registro na ANVISA. O acórdão está acessível no site do Tribunal. O voto do relator, Ministro Benedito Gonçalves, está disponível em: https://ww2.stj.jus.br/websecstj/ cgi $/$ revista $/$ REJ.cgi/ATC seq $=76923856 \&$ tipo $=91 \& \mathrm{nreg}=201700256297 \&$ SeqCgrmaSessao $=\&$ CodOrgaoJgdr $=\& \mathrm{dt}=20$ 180504\&formato=PDF\&salvar=false. Acesso em: 9 out. 2018. De qualquer forma, como o tema envolve a apreciação de direitos fundamentais, invariavelmente o Supremo Tribunal Federal seria provocado a decidir. O Recurso Extraordinário n. 566.471/RN examinou apenas a questão de medicamentos, porém a ratio decidendi fatalmente será análoga para embasar decisões sobre tratamentos e demais serviços sanitários. O Supremo Tribunal negou-lhe provimento em 11/3/2020 e admitiu que, excepcionalmente, poderiam ser fornecidos medicamentos não dispostos nas políticas sanitárias, porém o julgamento ainda não foi concluído, porque faltam os Ministros deliberarem e tentarem uniformizar os parâmetros para que isso seja feito. O Recurso Extraordinário n. 657.718/MG referia-se exclusivamente a medicamentos não registrados pela ANVISA. Porém, o plenário do Supremo Tribunal Federal decidiu a questão em 22/5/19, redator para acórdão o Ministro Luís Roberto Barroso, fixando-se a seguinte tese, não tendo sido o acórdão publicado ainda: "1. O Estado não pode ser obrigado a fornecer medicamentos experimentais. 2. A ausência de registro na ANVISA impede, como regra geral, o fornecimento de medicamento por decisão judicial. 3. É possível, excepcionalmente, a concessão judicial de medicamento sem registro sanitário, em caso de mora irrazoável da ANVISA em apreciar o pedido (prazo superior ao previsto na Lei n. 13.411/2016), quando preenchidos três requisitos: (i) a existência de pedido de registro do medicamento no Brasil (salvo no caso de medicamentos órfãos para doenças raras e ultrarraras); (ii) a existência de registro do medicamento em renomadas agências de regulação no exterior; e (iii) a inexistência de substituto terapêutico com registro no Brasil. 4. As ações que demandem fornecimento de medicamentos sem registro na ANVISA deverão necessariamente ser propostas em face da União"Como, em regra, o medicamento só pode ser incluído no catálogo do SUS se possuir registro na ANVISA (art. 19-T da Lei n. 8.080/90), entende-se que o problema central se concentra na questão objeto do Recurso Extraordinário n. 566.471/RN, razão pela qual a falta de registro da ANVISA não será trabalhada no texto. 
todo caso difícil, a resposta judicial advirá pela aplicação de um princípio jurídico, o que poderá envolver um juízo ponderativo inequívoco para solucionar o conflito entre o direito à saúde do demandante e o direito à saúde de terceiros (ALEXY, 2008, p. 94-98; BARROSO, 2010b, p. 876 e ss.; DUARTE, 2006; p. 151 e 237-295). ${ }^{5}$

Há um certo consenso entre os juristas que se alinham à defesa da ponderação contra as críticas de subjetivismo e irracionalidade - feitas, por exemplo, por Aleinikoff ([entre 1986 e 1987], p. 948 e ss.) e Habermas (2005, p. 311-361). Para os adeptos do sopesamento, a melhor ferramenta heurística para dar maior objetividade ao sopesamento e, assim, torná-lo mais racional, é a aplicação da norma da proporcionalidade e de seus subtestes: legitimidade do fim, idoneidade e necessidade do meio e proporcionalidade em sentido estrito (ALEXY, 2000, p. 297; ÁVILA, 2008, p. 134-145; SILVA, 2002, p. 25-26).

Não obstante, ainda que se perfile ante essa matriz teórica, há uma possibilidade de acréscimo na racionalidade ponderativa. Nesse diapasão, a experiência judicial norte-americana de categorizar precedentes, vinculando as decisões a padrões e níveis de intensidade da revisão da ponderação legislativa definidos de modo predeterminado pelo corpo de jurisprudência do tribunal, de sorte a pretender universalizar a regra de decisão obtida no sopesamento a casos futuros, é uma forma viável de minorar o casuísmo e agregar maior segurança jurídica (NOVAIS, 2003, p. 908-951; NOVAK, 2010, p. 101-112). De fato, o exemplo mais célebre de categorização de jurisprudência constitucional é dado pela Suprema Corte dos Estados Unidos. Alguns direitos, como liberdade de expressão e de imprensa, são sindicados por um escrutínio estrito (strict scrutiny), em que o controle é mais intenso e exige-se que a restrição persiga um fim que seja cogente e imperativo. Uma segunda categoria de direitos possui um escrutínio de intensidade intermediária (intermediate review), como a liberdade de expressão em ambientes públicos, a cláusula da igual proteção quando o critério diferenciador for com base em gênero ou idade (categorias quase-suspeitas), em que basta que o Legislativo persiga um interesse significativo ou importante. Por fim, com maior dose de deferência, existe a categoria dos direitos submetidos ao rational basis review, a exemplo de diferenciações promovidas em outros critérios não suspeitos ou o controle de constitucionalidade de legislação de cunho econômico-social, em que a Corte contenta-se a examinar se há um interesse estatal legítimo perseguido pela norma jurídica (ALMEIDA, 2013, p. 62 e ss.; BARAK, 2012, p. 245-302; PHILIPPE, 1990, p. 32-41).

Assim, o padrão do conteúdo mínimo pode fazer essa função de acréscimo de racionalidade jurídica ao ser acoplado à norma da proporcionalidade. No entanto, deve-se explicar em que acepção se compreende o padrão em tela e qual a sua virtualidade de emprego no escrutínio de direitos fundamentais sociais. Outrossim, é imprescindível que se utilizem parâmetros normativos

\footnotetext{
Embora Dworkin defenda a aplicação de princípios jurídicos para a solução de casos difíceis, ele não aparenta ser adepto da ponderação, matriz teórica adotada no texto, em função de advogar uma única resposta correta para solução de casos jurídicos.
} 
que norteiem o Judiciário na construção do conteúdo mínimo do direito à saúde. Sobreleva essa inferência diante do fato de que o Supremo Tribunal Federal, embora já tenha decidido que é possível o fornecimento de medicamento não disponibilizado pelo SUS em caráter excepcional, não definiu ainda os critérios ou parâmetros para assim proceder.

Destarte, centra-se o artigo no estudo do conteúdo mínimo do direito à saúde e dos parâmetros normativos de sua definição. Para tanto, assume-se como marco teórico as obras de juristas que advogam a possibilidade de conflitos normativos e sua solução pela via ponderativa (a exemplo de David Duarte e Robert Alexy), estruturada pela norma da proporcionalidade, as quais, todavia, não serão objeto de reflexão neste texto. Finalmente, o pensamento aqui construído foi embasado no método dedutivo, com pesquisa bibliográfica de textos normativos e doutrinários do Direito, bem como com a leitura de algumas decisões e votos de órgãos jurisdicionais.

\section{Conceito e função do conteúdo mínimo}

O conteúdo mínimo foi inspirado e derivado da garantia do núcleo essencial dos direitos fundamentais, esta positivada pela primeira vez na Constituição alemã de 1949 (art. 19, $2^{\circ}$ ), também inserida nas Constituições portuguesa de 1976 (art. 18 , 3) e espanhola de 1978 (art. 53, I). O núcleo essencial funcionaria como mais um "limite dos limites", de forma a impedir que, no exercício de criação da legislação e na fixação de restrições aos direitos fundamentais, o Parlamento esvaziasse o conteúdo do direito de qualquer utilidade prática (ALMEIDA, 2014, p. 245 e ss.; ALMEIDA, 2011, p. 225 e ss.; LOPES, 2004, p. 7-8; PINTO, 2001, p. 1095 e ss.).

Em relação à garantia do núcleo essencial, desenvolveram-se várias teorias, não havendo consenso doutrinário sobre a sua utilidade, simbologia ou superfluidade para a tutela dos direitos fundamentais (ALMEIDA, 2014, p. 247 e ss.; ALMEIDA, 2011, p. 226 e ss.; HÄBERLE, 2003, p. 219220; NOVAIS, 2003, p. 779-780). Seguramente, o principal debate sobre o núcleo essencial reside em como defini-lo, se de modo absoluto ou relativo (NOVAIS, 2003, p. 782-799; SILVA, 2009, p. 185200). A teoria absoluta propõe um núcleo material insuscetível de restrições, independentemente das circunstâncias do caso concreto. A teoria relativa propugna que sua delimitação exsurgirá após um exame de proporcionalidade, de forma que o âmbito protegido da intervenção excessiva do legislador é variável. Há, ainda, tentativas de teorias mistas, no afã de enfrentar os problemas advindos pela adoção pura de uma teoria absoluta ou relativa.

De qualquer maneira, de plano observa-se que a garantia do conteúdo essencial foi pensada de modo originário para proteger contra uma atuação excessiva do Parlamento no estabelecimento de restrições aos direitos fundamentais. Não havia a preocupação com a salvaguarda do déficit de proteção, que se eleva no caso de deveres estatais positivos extraídos das normas de direitos fundamentais, mormente dos direitos sociais. 
A adaptação da garantia do núcleo essencial aos direitos sociais deve-se em boa medida ao Comitê de Direitos Econômicos, Sociais e Culturais da Organização das Nações Unidas. O Comitê, que tomou para si a missão de realizar interpretações do Pacto Internacional de Direitos Econômicos, Sociais e Culturais de 1966 por meio de comentários gerais, procurou extrair uma interpretação que não deixasse os direitos econômicos, sociais e culturais ao desabrigo de proteção jurídica. Afinal, o Pacto, no seu artigo $2^{\circ}$, positiva o caráter progressivo do cumprimento dos deveres pelos Estados, o que poderia dificultar o exame desse adimplemento e de sua efetivação (ALMEIDA, 2014, p. 248 e ss.; ALMEIDA, 2011, p. 228 e ss.).

No Comentário Geral n. 3, o Comitê proclamou que só a legislação não representa o cumprimento dos deveres estatais, pois todas as medidas possíveis devem ser encetadas, observado o máximo de recursos disponíveis. Sem prejuízo dessa premissa, o Comitê levanta a tese de que é possível configurar um núcleo mínimo dos direitos sociais, o qual deve contar com remédios judiciais para sua proteção. Com isso, a lógica do Comitê é de que a satisfação progressiva dos direitos sociais deve ser buscada sem retrocessos, salvo se houver justificação legítima para tanto. Para as obrigações definidas no conteúdo mínimo, o seu descumprimento só não será considerado como violação dos direitos previstos no Pacto se ficar provada a absoluta impossibilidade financeira de realizá-las, ônus de prova e de argumentação atribuíveis ao Estado (ALMEIDA, 2014, p. 248 e ss.; ALMEIDA, 2011, p. 231 e ss.).

Como, porém, definir o que compõe o conteúdo ou núcleo mínimo? Young (2008, p. 126264) adverte que a estratégia de obrigações mínimas proposta pelo Comitê não é o único modo de conceber o núcleo mínimo. Uma segunda abordagem é a "essencialista", em que se pode defender uma concepção material de núcleo mínimo ora centrada nas necessidades básicas, ora em princípios materiais reconhecidos no sistema, como a dignidade humana. Uma terceira abordagem, por sua vez, é de cunho consensualista, consoante prática reconhecida mutuamente entre os países ou consoante sedimentado na jurisprudência internacional. Haveria problemas em qualquer delas: uma definição material traz o problema da controvérsia e fluidez do núcleo, o que enfraquece a tutela que poderia fornecer; uma definição consensual protege muito pouco, pois só um piso muito ao rés do chão poderia permitir algum tipo de concordância mútua; uma definição por obrigações mínimas traz o problema da policentricidade (ALMEIDA, 2014, p. 253 e ss.; ALMEIDA, 2011, p. 236 e ss.; FULLER, [entre 1978 e 1979], p. 393-409) das obrigações, havendo fluidez naquilo que seria considerado essencial e naquilo que seria periférico ou aureolar do conteúdo do direito.

No entanto, o núcleo ou conteúdo mínimo pode ser útil como padrão adicional ao uso da norma da proporcionalidade. $\bigcirc$ âmago da resistência à concepção essencialista retorna ao cerne do debate sobre as teorias absoluta e relativa do núcleo essencial dos direitos fundamentais. Como há uma série de circunstâncias econômicas, políticas, culturais, sociais e até históricas que podem ser decisivas para a resolução do caso, é natural que o núcleo mude ao longo do tempo e conforme o grau de desenvolvimento socioeconômico. Assim, é mais lógico partir para uma teoria relativa, uma vez que, por mais desejável que seja a segurança jurídica, não é viável que a jurisdição constitucional 
revista-se de "um olhar de Medusa" sobre as questões que the são submetidas, porquanto seria malfadada qualquer tentativa de petrificação da jurisprudência (ALMEIDA, 2014, p. 255).

A maior crítica a uma teoria relativa, porém, alicerça-se na dispensabilidade da garantia do núcleo essencial, porquanto não protegeria nada além daquilo salvaguardado pela norma da proporcionalidade. Sem embargo, é possível encontrar uma função dogmática autônoma do padrão do conteúdo mínimo, de certa forma conciliando a concepção advogada pelo Comitê de Direitos Econômicos, Sociais e Culturais com a defesa de uma teoria relativa. Isso porque o Comitê percebe o conteúdo mínimo como obrigações básicas imediatamente exigíveis, mesmo que haja omissão legislativa, no entanto reconhece a possibilidade de que haja justificação legítima para a omissão estatal, cujo ônus de prova incumbe ao Estado. Desse modo, mais que uma função meramente proclamatória ou declarativa, o núcleo ou conteúdo mínimo, entendido como as obrigações básicas imediatamente exigíveis, poderia servir como uma divisor do ônus de argumentação e de controle da esfera judicial. Com efeito, consoante os conflitos normativos que envolvam direitos sociais sejam dirimidos por juízo ponderativo empregando a norma da proporcionalidade, será possível que os tribunais enumerem os deveres mínimos que compõem a esfera nuclear do direito. Logo, obrigações enquadráveis dentro do conteúdo mínimo seriam prima facie exigíveis, de sorte que a não prestação demandará do ente público altos ônus de argumentação e de prova, com maior grau de controle judicial da conduta estatal. Ao revés, prestações não integrantes do conteúdo nuclear resultam em um grau de controle mais enfraquecido pelo Judiciário, com menores ônus de argumentação e de prova atribuíveis ao Estado (ALMEIDA, 2014, p. 252 e ss.; ALMEIDA, 2011, p. 238 e ss.).

Com isso, o conteúdo mínimo conforma-se como um padrão que parametriza e categoriza a jurisprudência constitucional dos direitos sociais. Afinal, se em jogo estiverem prestações definidas no conteúdo mínimo, haverá maior fardo de argumentação e de prova a cargo do Estado e, salvo se houver justificação legítima, devem ser fornecidas. Obrigações não nucleares, por sua vez, demandarão um controle mais enfraquecido e com menores ônus de justificação e de prova atribuíveis ao ente público. A funcionar assim, o núcleo mínimo permite maior estabilização e segurança jurídica, dá maior orientação às instâncias inferiores e ganha autonomia dogmática em relação à norma da proporcionalidade, a servir como um padrão adicional que orientará as ponderações futuras, pois haverá uma regra de decisão universalizável para solver os futuros conflitos normativos. De outro lado, preserva também um pouco de fluidez na sua formatação, porquanto será possível que obrigações não nucleares passem a compor a esfera nuclear conforme sucessivas soluções de conflitos normativos do direito fundamental social, com suas ponderações, resultem no dever de prestá-las (ALMEIDA, 2014, p. 252-259). Em realidade, é preciso, também, incorporar na mentalidade dos juízes que a alteração da jurisprudência só será admissível mediante a superação de um "limiar epistêmico" (PERRY, [entre 1996 e 1997], p. 787-819), para o qual não basta a convicção do julgador presente de ter melhor solução que a que foi dada no passado pelos precedentes, mas sim que essa 
mudança só será viável se a replicação da solução passada for manifesta e extremamente inadequada para os casos futuros.

Mas existe base jurídico-positiva para adotar a teoria do núcleo mínimo no Brasil? Indubitavelmente, a par do pragmatismo, deriva-se o conteúdo mínimo da garantia de acesso à jurisdição conjugada com a competência judicial de controle de constitucionalidade e com a aplicabilidade imediata das normas de todos os direitos fundamentais (art. $5^{\circ}, \$ 1^{\circ}$ ), o que gera a inferência da existência de um piso básico de situações e posições jurídicas com eficácia e preceptividade ainda que não exista maior densificação ou concretização do direito fundamental pela legislação (ALMEIDA, 2014, p. 262-263).

Como epílogo desta seção, é relevante entender se o conceito e a função de núcleo ou conteúdo mínimo equivalem à definição e ao papel do mínimo existencial. ${ }^{6} \mathrm{O}$ berço da tese do mínimo existencial encontra-se na Alemanha. O Tribunal Constitucional Federal alemão fez referência a ele pela primeira vez no precedente sobre a assistência social de 1975, BVerfGE 40,121 (SCHWABE, 2005, p. 827 e ss.). Embora tenha declarado a constitucionalidade da lei que fixou o limite de 25 anos aos portadores de incapacidade física ou mental para recebimento da pensão por morte, a Corte tedesca salientou a existência de uma obrigação de índole objetiva que paira sobre o Legislativo de auxílio aos necessitados, prescrita pelo princípio do Estado Social e cuja conformação da forma e da extensão do adimplemento cabia discricionariamente ao próprio Parlamento, observados, porém, os "pressupostos mínimos", o que leva alguns juristas a defender o mínimo existencial como um direito originário a prestações implícito no texto constitucional alemão (ALEXY, 2008, p. 436-437 e ss.).

O mínimo existencial é normalmente associado com a dignidade humana (MIRANDA, 2008, p. 430). No entanto, não há um consenso sobre o conceito de mínimo existencial nem de sua função. De um modo geral, na Europa, a principal roupagem do mínimo existencial está na garantia de assistência social. Na Alemanha, em que sua Constituição (ALEMANHA, 1949) não previu, em regra, direitos fundamentais sociais, dividiu-se a doutrina sobre a questão de o mínimo existencial limitar-se ao mais básico fisiologicamente, atrelando-o ao direito à vida e à dignidade humana, ou se ele seria composto de uma vertente sociocultural, trabalhada como decorrência do Estado Social e do princípio da igualdade, a alicerçar também prestações culturais necessárias à inclusão do indivíduo na vida social com igualdade de oportunidades (SARLET; FIGUEIREDO, 2010, p. 19-27).

Em Portugal, diverge-se sobre a sua natureza. Andrade (2009, p. 376 e ss.) situa-o como um direito de liberdade, cuja consequência é um dever negativo de não suprimir nem tributar prestações estatais essenciais para a sobrevivência e um padrão básico de dignidade da pessoa. Queiroz (2006, p. 162) apregoa-o como direito social com a natureza de regra jurídica, aplicável por subsunção e não por ponderação. Canotilho (2008, p. 54-59) trata-lhe como um direito público subjetivo, um direito originário a prestações, correlacionado também ao direito à vida, o qual será exigível se

\footnotetext{
$\overline{6}$ Sobre a reflexão do conceito e da função do mínimo existencial, conferir Almeida (2014, p. 149 e ss.).
} 
houver circunstâncias do caso concreto que eliminem a margem de discricionariedade normalmente outorgada ao Parlamento para prever a extensão e a forma de adimplemento desse dever.

Em solo pátrio, nota-se que há uma divergência sobre se o mínimo existencial representa uma expressão sinônima àquela de núcleo ou conteúdo essencial dos direitos sociais ou se se trataria de aquilo que é garantido pelos direitos sociais ou passível de ser judicializável (SILVA, 2009, p. 204-207). Há quem pretenda que o mínimo englobe um conjunto de necessidades e direitos essenciais aos seres humanos (LEIVAS, 2010, p. 300-301). Torres (2010, p. 69-76) enquadra o mínimo existencial no rótulo de "verdadeiros direitos fundamentais sociais", pois prescinde de lei ordinária e não se limita pela reserva do possível, embora não possa o Judiciário determinar a integração da lacuna orçamentária pelo Judiciário, que deverá remeter aos outros Poderes a realização dos atos orçamentários. Finalmente, é útil registrar a opinião de Sarlet e Figueiredo (2010, p. 19-27), para quem o mínimo existencial é um direito autônomo aos direitos fundamentais sociais, composto de prestações mais básicas para uma vida digna (saudável), não se confundindo com o núcleo essencial dos direitos fundamentais sociais, embora seja possível alguma sobreposição; os juristas afastam a possibilidade de um arrolamento taxativo do mínimo, pois se deve examinar sempre o caso concreto.

A rigor, a origem da tese do mínimo existencial está em uma ordem jurídico-constitucional que praticamente não positivou direitos fundamentais sociais, em que a preocupação era evitar que a penúria individual malferisse a dignidade a ponto de frustrar uma mínima possibilidade de livre desenvolvimento da personalidade. Por que fazer empréstimo de uma teoria desenvolvida nesse quadrante para um ordenamento jurídico-constitucional que prevê direitos fundamentais sociais, como ocorre com Brasil e Portugal? Por que importá-la para um arcabouço constitucional que previu a aplicabilidade imediata de todos os direitos fundamentais (caso brasileiro)? Como não há muito consenso sobre o que realmente significa o mínimo existencial e tendo em vista que a Constituição brasileira previu muitos direitos fundamentais sociais na forma de princípios sem que possam receber a qualificação de direitos mais básicos, é possível, com vantagem, abandonar o conceito de mínimo existencial para concentrar a reflexão e a análise na tentativa de elaborar um conteúdo mínimo ou essencial de cada direito fundamental social, exigível independentemente de concreção legislativa, algo próximo à estratégia desenvolvida pelo Comitê de Direitos Econômicos, Sociais e Culturais (ALMEIDA, 2014, p. 153; NOVAIS, 2010, p. 197-199).

Apresentados o conceito e função do conteúdo ou núcleo mínimo, passa-se a verificar os parâmetros normativos que devem nortear a sua formatação, com a lupa voltada para o caso do direito à saúde?

\footnotetext{
É preciso dizer, porém, que o Comitê alterou, ao menos no que toca ao direito à saúde, parcialmente sua concepção de conteúdo mínimo. No comentário geral n. 14, no parágrafo 43, o Comitê enumera as seguintes obrigações nucleares: a) direito de acesso não discriminatório às instalações, bens e serviços de saúde, com mais razão assegurado a grupos vulneráveis e marginalizados; b) direito à alimentação essencial mínima, segura e nutricionalmente adequada; c) direito de acesso a moradia ou abrigo e saneamento básico, além de água potável; d) fornecer medicamentos essenciais, conforme definição da Organização Mundial da Saúde; e) equidade na distribuição de bens, instalações e serviços de saúde; f) elaborar estratégia e plano nacional de saúde, o qual deve ser periodicamente revisto, observada a participação transparente da população na sua
} 


\section{Parâmetros normativos e o núcleo mínimo do direito à saúde no Brasil}

Em tese, é possível enumerar o conjunto de obrigações mínimas que integrariam o conteúdo mínimo. Essa apreciação poderia ser com base em um juízo normativo, em que se propõe quais deveriam ser as prestações incluídas na esfera nuclear mínima conforme critérios jurídicos assumidos pelo proponente, ou em um viés preponderantemente descritivo, em que se examinaria o corpo de jurisprudência e eventualmente seriam pinçadas as obrigações assim reconhecidas pelo próprio Judiciário. ${ }^{8}$

Uma tentativa de enumerar o núcleo mínimo poder-se-ia aproveitar da doutrina de Barcellos (2010, p. 810-815), a qual, porém, refere-se ao mínimo existencial. A jurista, que argumenta estar baseada em uma construção consensualista, defende que componham o mínimo existencial todas as prestações de saúde de que as pessoas já necessitaram, necessitam ou irão necessitar provavelmente. Assim, exemplificativamente, a autora menciona que todos já precisaram de cuidados pré-natais, no parto e pós-natais, todos necessitam de saneamento básico e atendimento preventivo em clínicas gerais e especializadas e há probabilidade de que todos dependerão de acompanhamento e controle das enfermidades características da terceira idade. Outrossim, amparada na Lei n. 9.658/98, Barcellos afirma que o mínimo existencial se compõe do pacote mais básico de serviços de saúde fornecido por seguros privados: atendimento ambulatorial, com cobertura de consultas médicas em clínicas básicas e especializadas, serviços de apoio de diagnóstico, tratamentos e procedimentos ambulatoriais.

Uma primeira observação, consoante exposto na seção precedente, é que núcleo mínimo ou mínimo existencial não se equivalem necessariamente. De qualquer maneira, nada impede que se utilize a expressão "mínimo existencial" no mesmo sentido dado a núcleo ou conteúdo mínimo ou essencial, porém isso resulta no ônus adicional de explicar qual o sentido dado a essa expressão polissêmica.

O maior problema da tese da autora, tal qual ocorre com a proposta de obrigações básicas trazidas pelo Comitê de Direitos Econômicos, Sociais e Culturais no comentário geral n. 14, ${ }^{9}$ é não admitir, em nenhuma hipótese, justificativa legítima para o inadimplemento, o que reveste o conteúdo mínimo (chamado por ela de mínimo existencial) de um matiz absoluto incompatível com a teoria relativa que se pensa mais correta. Em realidade, a proposta aqui defendida situa o

\footnotetext{
elaboração, com atenção especial aos grupos marginalizados. Ocorre que o Comitê, nos parágrafos 47 e 48 do comentário geral, termina por tornar absoluto o núcleo mínimo, uma vez que não considera legítima, em nenhuma hipótese, sua não prestação.

8 Para uma tentativa enumerar as obrigações constantes do conteúdo mínimo do direito à educação no sistema regional africano, em cotejo com o núcleo mínimo desenhado no comentário geral n. 13 do Comitê de Direitos Econômicos, Sociais e Culturais, bem como de extrair, por indução, o conteúdo mínimo do direito à instrução com base na jurisprudência da Corte Europeia de Direitos do Homem, Almeida (2011, p. 261-268 e 287-301).

9 Conferir nota de rodapé n. 6.
} 
núcleo mínimo como um padrão adicional ao exame de proporcionalidade, com a virtualidade de universalizar a regra de decisão a ponderações futuras mediante a categorização da jurisprudência.

Não obstante a possibilidade e a utilidade de descrição ou proposição do conjunto de prestações incluídas no conteúdo mínimo, pensa-se que é mais interessante centrar esforços na delimitação de parâmetros normativos que possam ser empregados pelo Judiciário na construção do conteúdo nuclear do direito.

Ab ovo, enumeram-se os seguintes parâmetros normativos:
a) dignidade da pessoa humana;
b) solidariedade do Estado;
c) isonomia;
d) eficiência ou prioridade da solução mais econômica;
e) ônus da prova;
f) prioridade das ações coletivas às individuais;
g) ampliação do diálogo interinstitucional (ALMEIDA, 2014, p. 292-298). Os quatro primeiros são parâmetros materiais, ao passo que os demais são parâmetros procedimentais.

O princípio da dignidade humana encontra abrigo positivo no art. 1º, III, da Constituição Federal (BRASIL, 1988). Como leciona Alexandrino (2011, p. 15-41), há três concepções diversas de dignidade. A teoria da dádiva, sustentada por Kant, desenha a dignidade em um prisma ontológico, uma realidade assente na natureza do próprio homem enquanto ser vivente. A teoria funcional ou da prestação, encontrada em Luhmann, representa a dignidade como algo dependente da ação do próprio indivíduo, um ativo forjado conforme o ser humano comporta-se responsavelmente enquanto desenvolve sua autonomia. A teoria do reconhecimento, de Hofmann, relaciona a dignidade com a solidariedade, conformada naquilo que se reconhece no outro. Portanto, se é fato que a dignidade possui uma inextrincável vagueza semântica, não menos certo que ela deve ser compreendida não só em um prisma individual, mas também comunitário e com autonomia de vontade (BARROSO, 2010a, p. 1-30).

Entrementes, é indubitável que uma prestação sanitária indispensável para a vida digna é um fator importante que influenciará o sopesamento judicial, como se percebe do magistério de Sarlet e Figueiredo (2010, p. 19-27), os quais apresentam um conceito de mínimo existencial norteado pelo exercício de vida saudável. Na seara da saúde, com a premissa de que as necessidades são variáveis ao longo do espaço/tempo (DALLARI, 2013, p. 26 e ss.; LOUREIRO, 2006, p. 660-663 e 672-676), invariavelmente no primeiro elemento desse binômio adere-se um aspecto cultural, revestido de uma nota expansiva. Deveras, a dignidade humana reveste-se de uma potência de crescimento e dinamismo (MARQUES, 2010, p. 541-566), a funcionar como um critério de atualização do núcleo mínimo do direito à saúde. 
Ora, considerado o direito à saúde como um princípio jurídico, com integração de um aspecto de funcionamento normal do corpo humano e de atendimento de necessidades básicas em saúde (DANIELS, 2001, p. 2 e ss.; DANIELS, 2009, p. 9-18), ${ }^{10}$ as posições e situações jurídicas que sejam reflexo dessas carências sanitárias consubstanciam um viés de dignidade inafastável, muito compatível com os adeptos de uma noção filosófica de justiça distributiva (SCHACHTER, 1983, p. 848-852). Os votos dos Ministros Marco Aurélio, Luís Roberto Barroso, Edson Fachin e Gilmar Mendes no Recurso Extraordinário n. 566.471/RN11 e o acórdão no Recurso Especial n. 1.657.156/ RJ (BRASIL, 2017a) reforçaram a necessidade sanitária do indivíduo, de sorte que se conclui que percebem a dignidade integrada ao próprio conteúdo do direito à saúde. Não obstante, seria um exagero aduzir que toda carência sanitária seja uma violação da dignidade. Nesse ponto, há uma preferência no entalhe do conteúdo mínimo por ações e cuidados preventivos e, em seguida, os que evitem a morte, desde que seja possível a recuperação do funcionamento padronizado do organismo, ou seja, curar o indivíduo ou reabilitá-lo para a realização de suas atividades cotidianas. De outro lado, cuidados paliativos ou que prolonguem a vida, caso não haja perspectiva de cura ou reabilitação, possuem uma força argumentativa menor, a não ser que exista uma completa omissão estatal, isto é, uma ausência total de previsão de alguma política pública gizada para aquela moléstia e, concomitantemente, uma limitação severa trazida pela enfermidade.

O parâmetro material da solidariedade radica-se nos objetivos fundamentais da nossa República de construir uma sociedade livre, justa e solidária, erradicar a pobreza e reduzir as desigualdades (art. $3^{\circ}$, I e III, Constituição Federal) (BRASIL, 1988). Se é (ou deveria ser) a fraternidade a força motriz da democracia brasileira, a prioridade na canalização dos recursos é da atenção aos carentes economicamente se não for possível satisfazer aos reclamos de todos, porquanto deve ser considerado o aumento das demandas em saúde e dos custos, o que obriga a racionalizar e racionar os recursos (CALLAHAN, 1992, p. 6 e ss.). Especificamente no Brasil, onde ainda impera um modelo de judicialização de ações individuais, a solidariedade será fundamental porque obriga a investigar a renda e a situação financeira do autor da ação, tendo em vista que a diretriz é de que não se onere o Estado caso a pessoa possa adquirir por si o produto ou o serviço no próprio mercado (FRANCISCO, 2010, p. 859-873; HENRIQUES, 2010, p. 827-840; LIMA, 2010, p. 246-252; PERLINGEIRO, 2014,

\footnotetext{
10 O conceito de saúde como o funcionamento padrão do indivíduo é apresentado por Norman Daniels (DANIELS, 2001, p. 2 e ss.; DANIELS, 2009, p. 9-18), o qual adapta a teoria da justiça de Rawls ao agregar um caráter equitativo sobre a igualdade formal de oportunidades, segundo elemento do princípio da diferença da teoria rawlsiana, uma vez que reconhece que a satisfação das necessidades sanitárias é essencial para uma justa igualdade de oportunidades.

11 Os votos dos Ministros foram obtidos pela internet, à exceção do voto do Ministro Fachin, o qual não se tem certeza se é apenas um resumo ou já a versão integral do voto. O voto do Ministro Marco Aurélio (BRASIL, 2017c) está disponível em: http://www.stf.jus.br/arquivo/cms/noticiaNoticiaStf/anexo/RE566471.pdf. Acesso em: 20 mar. 2017. O voto do Ministro Barroso (BRASIL, 2017b) está disponível em: https://www.jota.info/wp-content/uploads/2016/09/RE-566471-Medicamentos-de-alto-custo-vers\%C3\%A3o-final.pdféx48657. Acesso em: 20 mar. 2017. O resumo do voto do Ministro Fachin (BRASIL, 2017d) está disponível em: https://www.conjur.com.br/dl/resumo-voto-fachin-re-566471.pdf. Acesso em: 20 mar. 2017. O voto do Ministro Gilmar Mendes (BRASIL, 2020) está disponível em: https://www.conjur.com.br/dl/voto-ministro-gilmar-mendes.pdf. Acesso em: 3 abr. 2020. $\mathrm{O}$ acórdão não foi publicado, de modo que não se obtiveram os demais votos.
} 
p. 580-583; SOUZA NETO, 2010, p. 539-540). Vale salientar que os votos dos Ministros Marco Aurélio, Luís Roberto Barroso, Edson Fachin e Gilmar Mendes dados no julgamento do Recurso Extraordinário n. 566.471/RN registraram que deveria estar comprovada no processo a insuficiência de renda do autor da ação, o que também foi reconhecido pelo Superior Tribunal de Justiça no Recurso Especial n. 1.657.156/RJ (BRASIL, 2017a). O Ministro Marco Aurélio ampliou o exame da hipossuficiência financeira ao estipular que se deveria respeitar o dever alimentar disposto no Código Civil, ou seja, o Estado só será responsabilizado caso não nem o autor nem os familiares sujeitos ao dever alimentar possam arcar com os custos da ação sanitária, o que é um contributo importante e deveria prevalecer. Já os Ministros Luís Roberto Barroso, Gilmar Mendes e Edson Fachin limitaram-se a pensar o parâmetro da solidariedade só com base na condição financeira do autor da ação. Seja como for, está claro que o debate é para a formação do conteúdo mínimo, exigível independentemente de legislação e previsão na própria política pública, o que não impede que os demais poderes, caso pretendam concretizar mais o conteúdo do direito, prevejam prestações de modo universal sem qualquer lastro na capacidade econômica.

O parâmetro material da igualdade finca-se no comando do art. $5^{\circ}$, caput, da Constituição Federal (BRASIL, 1988). Cada vez mais é necessário que o Judiciário, ao decidir as lides sanitárias, ainda que individuais, tenha em conta o impacto global a ser produzido no orçamento. No caso de ações individuais, é preciso avaliar não apenas o custo para a prestação individual reclamada, mas examinar o impacto potencial gerado por um efeito multiplicador de demandas ajuizadas por outros eventuais titulares em similares condições de carência sanitária (HENRIQUES, 2010, p. 827-840; SARMENTO, 2010, p. 569-572; SOUZA NETO, 2010, p. 539-540). Essa é a razão de, por exemplo, (PERLINGEIRO, 2014, p. 564 e ss.; PERLINGEIRO, 2013, p. 528-533) sugerir que seja judicializado o procedimento e não apenas a prestação, de sorte a permitir a universalização da medida sanitária caso haja êxito na demanda. A ideia é evitar o queue-jumping, o "furar fila", que sói ocorrer mormente na judicialização individual, uma vez que pessoas que tenham mais acesso à informação ou um acesso ao Judiciário mais facilitado conseguem passar na frente de outros que aguardaram na lista de espera sem judicializar e que podem até ter mais urgência no atendimento.

O critério da prioridade da solução mais econômica (SOUZA NETO, 2010, p. 542) é uma demonstração do atendimento ao princípio da eficiência (art. 37, caput, da Constituição Federal) (BRASIL, 1988). Considerando a escassez de recursos e sem prejuízo da proteção do direito fundamental, naturalmente haverá a cogitação de meios menos onerosos ao erário. Aliás, não deixa de ser uma consequência da própria norma da proporcionalidade, pois, na etapa da necessidade, é preciso examinar se há opção alternativa que proteja satisfatoriamente o direito fundamental e permita o fomento do fim na mesma potência. No teste da proporcionalidade em sentido estrito, ocasião em que se efetua o sopesamento com mais evidência, esse parâmetro entra na comparação com os meios alternativos previstos nas políticas públicas, isto é, nos medicamentos, tratamentos e ações sanitárias já previstos em programas do SUS. Afinal, na existência de opções padronizadas em protocolos clínicos e diretrizes 
terapêuticas que protejam suficientemente o direito à saúde, não há déficit na tutela. E mesmo que haja comprovação de maior eficácia ou segurança na promoção da saúde de determinado medicamento ou tratamento reclamado individualmente na lide, será necessário examinar o custo-efetividade do objeto da ação. Se o custo-efetividade for baixo, a força das razões do Estado aumenta. ${ }^{12}$ A propósito, nota-se que os votos dos Ministros Barroso e Fachin fazem referência a essa comparação de custoefetividade com as alternativas dispostas nas políticas do SUS, ao passo que o Ministro Gilmar Mendes condiciona a inexistência de substituto terapêutico previsto.

Ademais, se houver desproporcionalidade na omissão do Estado em prestar o medicamento ou serviço reclamado na ação, o parâmetro em tela demanda que haja cautelas impostas na própria ordem judicial, a fim de minorar os impactos financeiros no cumprimento da decisão. A esse respeito, podem ser pensadas algumas medidas, como a necessidade de renovação da avaliação médica para prestações continuadas, ${ }^{13}$ a cautela de orçamentos prévios caso não seja possível licitar o produto, ${ }^{14}$ a exigência de que a prescrição médica discrimine o princípio ativo e a denominação comum brasileira (DCB) ou a denominação comum internacional (DCI) e não o nome comercial do fármaco (DANTAS, 2013, p. 108-125), como salientado como preferência pelo Ministro Edson Fachin em seu voto para diminuir os impactos financeiros da decisão. ${ }^{15}$

Agora se passa ao exame dos parâmetros procedimentais. $\bigcirc$ primeiro deles preconiza que o ônus da prova é do Estado, encarregado de corroborar a escassez de recursos e o alto impacto financeiro da demanda, demonstrando, caso seja uma ação individual, o potencial de efeito multiplicador. Para desincumbir-se desse ônus, não basta só alegar, portanto, a reserva do possível, mas deve apresentar estudos, estatísticas e dados que comprovem em bases objetivas o possível universo de beneficiários da prestação demandada individual ou coletivamente, bem como o custo econômico de sua implantação universalizada. Também deverá demonstrar o prejuízo que o atendimento de eventual ordem judicial traria para outros direitos fundamentais e interesses promovidos pelo Estado. A par dessa percepção já enunciada pelo Comitê de Direitos Econômicos, Sociais e Culturais no comentário geral n. 3, há uma regra probatória geral prevista no art. 373 do Código de Processo Civil (BRASIL, 2015), de forma que incumbe ao réu demonstrar fatos extintivos, modificativos ou impeditivos do direito do autor. Deveras, em tempos de normalidade, não é possível associar a escassez alocativa de recursos a um fato notório, de sorte que admitir tal fato dependerá de um exame argumentativo das finanças e do orçamento do Estado.

\footnotetext{
12 Na doutrina havia vozes a sugerir o seguimento dos protocolos e diretrizes terapêuticas. Henriques (2010, p. 827-840), fala de um exame de razoabilidade para entregar a prestação não prevista nos protocolos clínicos e diretrizes terapêuticas. Barroso (2010b, p. 890-903), fala de uma preferência. Lima (2010, p. 250-252), defende a priorização dos tratamentos e medicamentos incorporados ao SUS, uma vez que os protocolos clínicos e diretrizes terapêuticas são uma racionalização do direito à saúde, ainda que não vinculantes ao Judiciário. Nas Jornadas de direito à saúde promovidos pelo CNJ, os enunciados n. 4 e 61 apresentam os protocolos clínicos e diretrizes terapêuticas como elementos de organização - e não de limitação - da assistência sanitária.

13 Enunciado n. 2 da I jornada de direito à saúde (BRASIL, 2018a).

14 Enunciado n. 56 da II jornada de direito à saúde (BRASIL, 2018b).

15 Ver, ainda, Dantas (2013, p. 108-125) e o enunciado n. 15 da I Jornada de Direito à Saúde (BRASIL, 2018a).
} 
parâmetro da prioridade das ações coletivas às individuais foi realçado na doutrina (BARCELLOS, 2010, p. 807-825; BARROSO, 2010b, 890-903; HENRIQUES, 2010, p. 827-840; LUPION, 2010, p. 316-318; SARMENTO, 2010, p. 583-585; SOUZA NETO, 2010, p. 543-545) e encontrou ressonância nos votos dos Ministros Fachin e Mendes. Obviamente, não se pode rejeitar uma ação individual pura e simplesmente, embora se possa defender a possibilidade em tese de sobrestamento da ação individual até o julgamento da ação coletiva (ALMEIDA, 2014, p. 297), mesmo que, para ficar clara essa possibilidade, fosse recomendável ajuste legislativo. De qualquer maneira, se voluntariamente os juízes não adotarem essa estratégia, o Conselho Nacional de Justiça seria de grande utilidade ao estipular recomendações e metas que dessem execução a esse parâmetro. De outra sorte, os autores de ações coletivas, especialmente o Ministério Público, devem incorporar esse critério para nortear sua atuação, inclusive, se for o caso, judicializando o próprio procedimento administrativo de modo coletivo, a fim de assegurar, em caso de vitória, a universalização da prestação.

O último parâmetro procedimental insiste no aumento do diálogo interinstitucional (SOUZA NETO, 2010, p. 506) e da interlocução com a sociedade, o que foi sugerido pelo Ministro Barroso em seu voto. $O$ acréscimo no colóquio entre os Poderes e instituições estatais e com a sociedade advém da realização de audiências e consultas públicas, o que permite a oitiva inclusive de especialistas na temática, a auxiliar a dirimir dúvidas sobre questões técnicas. Ora, é possível perceber que a audiência pública organizada pelo Supremo Tribunal Federal sobre a judicialização da saúde encontrou eco nos votos de alguns Ministros, como a ênfase dada pelos Ministros Barroso e Fachin na medicina baseada em evidências como meio de evitar o deferimento de toda e qualquer prestação sanitária ${ }^{16}$, a não concessão de produtos experimentais, a necessidade de examinar comparativamente o que é pedido com os medicamentos e serviços já incluídos no SUS, como proposto também pelo Ministro Gilmar Mendes. Outros pontos foram salientados em um ou outro voto, a exemplo da indicação da denominação comum brasileira (DCB) ou denominação comum internacional (DCI) e não o nome do fármaco.

Ex positis, o uso adequado desses parâmetros auxiliará o Judiciário a erigir um núcleo mínimo do direito à saúde, o qual, acoplado à norma da proporcionalidade, aumentará a racionalidade do sopesamento judicial e, dessa maneira, a segurança jurídica, algo que fortalece a legitimidade do Judiciário em efetuar o controle da satisfação desse direito fundamental e da própria política pública.

\section{Conclusão}

Sem desconhecer a competência judicial de controle de constitucionalidade e de sua função de salvaguarda contra violações de direitos fundamentais, inclusive por omissões estatais, o Poder Judiciário tem um sério desafio de legitimidade para o escrutínio de prestações na área da saúde

$\overline{16}$ Para uma definição de medicina baseada em evidências, remete-se a Maingué Neto (2011, p. 109-118). 
que não estão previstas nas políticas sanitárias. Diante de um cenário de escassez de recursos, um sistema de saúde universal como é o SUS deve fazer escolhas que possam otimizar o direito à saúde dentro do que é possível executar.

Ainda assim, justamente porque é possível que as seleções realizadas pelo Executivo terminem por proteger de modo insuficiente o direito fundamental à saúde, o Judiciário deverá necessariamente realizar um juízo ponderativo para decidir os "casos difíceis", o qual perpassa pelo exame de proporcionalidade. Sem embargo, para diluir a crítica de decisionismo ad hoc e para aumentar a racionalidade e segurança jurídica, é possível acoplar ao exame de proporcionalidade o parâmetro do conteúdo mínimo, o qual funcionará também como uma forma de categorização da jurisprudência a ser formada nesse domínio.

O conteúdo mínimo do direito à saúde - algo diverso da ideia de "mínimo existencial" - serve de bitola argumentativa, em que se acentuam os ônus de argumentação e de prova e a intensidade de controle jurisdicional caso em jogo estejam posições jurídicas do âmbito nuclear do direito fundamental. Como padrão adicional, aumenta a segurança jurídica das ponderações efetuadas no bojo de um controle pela norma da proporcionalidade. Prestações demandadas fora do núcleo ou conteúdo mínimo imporão, ao revés, um menor ônus de argumentação para o Estado e implicará um nível de intensidade de controle judicial mais débil.

A proposta feita neste texto é de sugerir os parâmetros que deverão orientar os tribunais na definição do conteúdo mínimo do direito à saúde. São eles: dignidade humana, solidariedade, isonomia, eficiência, ônus da prova, prioridade de ações coletivas e necessidade de aumento do diálogo interinstitucional.

Em relação à dignidade, não é toda a necessidade sanitária que a ofende: priorizam-se tratamentos preventivos e os que evitem a morte, caso seja possível o restaurar de um padrão de normalidade de funcionamento do organismo. Cuidados paliativos ou que prolonguem a vida, se inexistente a perspectiva de cura, tem menor força argumentativa, salvo se houver completa omissão estatal e se a limitação trazida for muito severa. Sobre a solidariedade, as prestações do conteúdo mínimo devem alcançar os carentes economicamente; deve a parte autora provar sua incapacidade financeira de adquirir os produtos. No que toca à igualdade, há um imperativo de universalizar as prestações, para evitar burla nas listas de espera.

Relativo à eficiência, podem ser determinadas cautelas para suavizar os impactos financeiros trazidos pelo cumprimento da decisão. Tangente ao ônus da prova, compete ao Estado provar a impossibilidade financeira de cumprir com a obrigação demandada, considerado o efeito multiplicador. O Judiciário deverá, também, priorizar o julgamento de ações coletivas às individuais, o que certamente trará maior conhecimento ao órgão judicante sobre o impacto da demanda e eventual falha ou não da tutela estatal ao direito. Finalmente, o aumento do diálogo interinstitucional combina uma cooperação entre os vários Poderes e especialistas e representantes da sociedade civil, o que permitirá uma fundamentação mais correta e diminuirá a chance de equívocos sobre aspectos técnicos que norteiam as políticas públicas. 


\section{Referências}

ALEINIKOFF, T. Alexander. Constitutional law in the age of balancing. Yale Law Journal, [S. l.], v. 96, n. 5, p. 943-1005, [entre 1986 e 1987].

ALEMANHA. Constituição. 1949. Disponível em: https://www.btg-bestellservice.de/pdf /80208000.pdf. Acesso em: 9 out. 18.

ALEXANDRINO, José de Melo. Perfil constitucional da dignidade da pessoa humana: um esboço traçado a partir da variedade de concepções. In: ALEXANDRINO, José de Melo (org.). O discurso dos direitos. Coimbra, Portugal: Coimbra Editora, 2011.

ALEXY, Robert. On the structure of legal principles. Ratio Juris, [S. l.], v. 13, n. 3, p. 294-304, 2000.

ALEXY, Robert. Teoria dos direitos fundamentais. Tradução: SILVA, Virgílio Afonso da. São Paulo: Malheiros, 2008.

ALMEIDA, Kellyne Laís Laburú Alencar de. A igualdade e a proporcionalidade - Reflexões sobre a ponderação do legislador e a ponderação do juiz nas ações afirmativas. In: DUARTE, David; SARLET, Ingo Wolfgang; BRANDÃO, Paulo de Tarso (coord.). Ponderação e proporcionalidade no Estado constitucional. Rio de Janeiro: Lumen Juris, 2013.

ALMEIDA, Luiz Antônio Freitas de. Direitos fundamentais sociais e ponderação - Ativismo irrefletido e controle jurídico racional. Porto Alegre: Sergio Antonio Fabris, 2014.

ALMEIDA, Luiz Antônio Freitas de. O núcleo mínimo dos direitos à educação e à instrução e o papel das Cortes africana e europeia de direitos do homem na sua garantia. In: ALEXANDRINO, José de Melo (coord.). Os direitos humanos em África. Coimbra, Portugal: Coimbra Editora, 2011.

ANDRADE, José Carlos Vieira de. Os direitos fundamentais na Constituição portuguesa de 1976. 4. ed. Lisboa, Portugal: Almedina, 2009.

ÁVILA, Humberto. Teoria dos princípios - Da definição à aplicação dos princípios jurídicos. 8. ed. São Paulo: Malheiros, 2008.

AZEVEDO, Paulo Furquim de et al. Relatório Analítico-Propositivo. Brasília, DF: CNJ/INSPER, 2019. (Série Justiça Pesquisa).

BARAK, Aharon. Proportionality - Constitutional rights and their limitations. Tradução: KALIR, Doron. Cambridge/New York: Cambridge University Press, 2012.

BARCELLOS, Ana Paula de. O direito a prestações de saúde: complexidades, mínimo existencial e o valor das abordagens coletiva e abstrata. In: SOUZA NETO, Cláudio Pereira; SARMENTO, Daniel (org.). Direitos sociais - Fundamentos, judicialização e direitos sociais em espécie. Rio de Janeiro: Lumen Juris, 2010.

BARROSO, Luís Roberto. A dignidade humana no direito constitucional contemporâneo: natureza jurídica, conteúdos minimos e critérios de aplicação (versão provisória para debate público). 2010a. Disponível: https://www.luisrobertobarroso.com.br/wp-content/uploads/2010/12/Dignidade_texto-base_ 11dez2010.pdf. Acesso em: 10 out. 2013. 
BARROSO, Luís Roberto. Da falta de efetividade à judicialização excessiva: direito à saúde, fornecimento gratuito de medicamentos e parâmetros para a atuação judicial. In: SOUZA NETO, Cláudio Pereira; SARMENTO, Daniel (org.). Direitos Sociais - Fundamentos, judicialização e direitos sociais em espécie. Rio de Janeiro: Lumen Juris, 2010 b.

BRASIL. Conselho Nacional de Justiça. Enunciados da I Jornada de Direito à Saúde. Disponível em: http://www.cnj.jus.br/images/ENUNCIADOS_APROVADOS_NA_JORNADA_DE_DIREITO_ DA_SAUDE_\%20PLENRIA_15_5_14_r.pdf. Acesso em: 9 out. 2018a.

BRASIL. Conselho Nacional de Justiça. Enunciados da II Jornada de Direito à Saúde. Disponível em: http://www.cnj.jus.br/files/conteudo/destaques/arquivo/2015/05/96b5b10aec7e5954fcc1978473e4cd80.pdf. Acesso em: 9 out. $2018 b$.

BRASIL. Constituição da República Federativa do Brasil de 1988. Diário Oficial da União, Brasília, DF, 5 out. 1988. Disponível em: http://www.planalto.gov.br/ccivil_03/Constituicao/Constituicao. htm. Acesso em: 9 out. 2018.

BRASIL. Lei n. 8.080, de 19 de setembro de 1990. Dispõe sobre as condições para a promoção, proteção e recuperação da saúde, a organização e o funcionamento dos serviços correspondentes e dá outras providências. Diário Oficial da União, Brasília, DF, 20 set. 1990. Disponível em: http:// www.planalto.gov.br/ccivil_03/leis/L8080.htm. Acesso em: 9 out. 2018.

BRASIL. Lei n. 13.105, de 16 de março de 2015. Código de Processo Civil. Diário Oficial da União, Brasília, DF, 17 mar. 2015. Disponível em: http://www.planalto.gov.br/ccivil_03/_Ato20152018/2015/Lei/L13105.htm. Acesso em: 9 out. 2018.

BRASIL. Superior Tribunal de Justiça. Recurso Especial n. 1.657.156/RJ. 2017a. Disponível em: https://ww2.stj.jus.br/websecstj/cgi/revista/REJ.cgi/ATC? seq $=76923856 \&$ tipo $=91 \&$ nre$\mathrm{g}=201700256297 \&$ SeqCgrmaSessao $=\&$ CodOrgaoJgdr $=\& \mathrm{dt}=20180504 \&$ formato $=$ PDF\&salvar $=-$ false. Acesso em: 9 out. 2018.

BRASIL. Supremo Tribunal Federal. Audiência pública: saúde. Brasília, DF: Secretaria de Documentação, 2009.

BRASIL. Supremo Tribunal Federal. Voto do Ministro Gilmar Mendes no Recurso Extraordinário n. 566.471/RN. Disponível em: https://www.conjur.com.br/dl/voto-ministro-gilmar-mendes.pdf. Acesso em: 3 abr. 2020.

BRASIL. Supremo Tribunal Federal. Voto do Ministro Luís Roberto Barroso no Recurso Extraordinário n. 566.471/RN. Disponível em: https://www.jota.info/wp-content/uploads/2016/09/RE-566471-Medicamentos-de-alto-custo-vers\%C3\%A3o-final.pdf?x48657. Acesso em: 20 mar. 2017b.

BRASIL. Supremo Tribunal Federal. Voto do Ministro Marco Aurélio no Recurso Extraordinário n. 566.471/RN. Disponível em: http://www.stf.jus.br/arquivo/cms/noticiaNoticiaStf/anexo/ RE566471.pdf. Acesso em: 20 mar. 2017c.

BRASIL. Supremo Tribunal Federal. Voto (ou resumo de voto) do Ministro Edson Fachin no Recurso Extraordinário n. 566.471/RN. Disponível em: https://www.conjur.com.br/dl/resumo-voto-fachin-re-566471.pdf. Acesso em: 20 mar. 2017d.

CALLAHAN, Daniel. Symbols, rationality, and justice: Rationing health care. American Journal of Law \& Medicine, [S. l.], v. 18, n. 1 e 2, p. 1-13, 1992. 
CANOTILHO, José Joaquim Gomes. Tomemos a sério os direitos económicos, sociais e culturais. In: CANOTILHO, José Joaquim Gomes (org.). Estudos de direitos fundamentais. 2. ed. Coimbra, Portugal: Coimbra Editora, 2008.

DALLARI, Sueli Gandolfi. Poderes republicanos e a defesa do direito à saúde - Evolução da proteção do direito à saúde nas constituições do Brasil. In: ALVES, Sandra Maria; DELDUQUE, Maria Célia; NETO, Nicolao Dino (org.). Direito sanitário em perspectiva. Brasília, DF: ESMPU: Fiocruz, 2013. v. 2 .

DANIELS, Norman. Justice, health, and healthcare. The American Journal of Bioethics, [S. 1.], v. 1, n. 2, p. 2-16, 2001.

DANIELS, Norman. L'extension de la justice comme équité à la santé et aux soins de santé. Tradução de Émmanuelle Glon. Raisons Politiques, Paris, n. 34, p. 9-29, 2009.

DANTAS, Eduardo Vasconcelos dos Santos. Droit médical au Brésil - Essais et réflexions sous la perspective du droit comparé. Rio de Janeiro: GZ Editora, 2013.

DUARTE, David. A norma da legalidade procedimental administrativa - A teoria da norma e a criação de normas de decisão na discricionariedade instrutória. Coimbra, Portugal: Almedina, 2006.

DWORKIN, Ronald. Levando os direitos a sério. Tradução: Nelson Boeira. 2. ed. São Paulo: Martins Fontes, 2007.

FRANCISCO, José Carlos. Dignidade humana, custos estatais e acesso à saúde. In: SOUZA NETO, Cláudio Pereira; SARMENTO, Daniel (org.). Direitos sociais - Fundamentos, judicialização e direitos sociais em espécie. Rio de Janeiro: Lumen Juris, 2010.

FULLER, Lon. The forms and limits of adjudication. Harvard Law Review, [S. l.], v. 92, p. 353-409, [entre 1978 e 1979].

HÄBERLE, Peter. La garantía del contenido esencial de los derecho/s fundamentales en la ley fundamental de Bonn. Tradução: Joaquín Brage Camazano. Madrid: Dykinson, 2003.

HABERMAS, Jürgen. Facticidad y validez. Tradução: Manuel Jiménez Redondo. 4. ed. Madrid: Editorial Trotta, 2005.

HENRIQUES, Fátima Vieira. Direito prestacional à saúde e atuação jurisdicional. In: SOUZA NETO, Cláudio Pereira; SARMENTO, Daniel (org.). Direitos Sociais - Fundamentos, judicialização e direitos sociais em espécie. Rio de Janeiro: Lumen Juris, 2010.

LEIVAS, Paulo Gilberto Cogo. Estrutura normativa dos direitos fundamentais sociais e o direito fundamental ao mínimo existencial. In: SOUZA NETO, Cláudio Pereira; SARMENTO, Daniel (org.). Direitos Sociais - Fundamentos, judicialização e direitos sociais em espécie. Rio de Janeiro: Lumen Juris, 2010.

LIMA, Ricardo Seibel de Freitas. Direito à saúde e critérios de aplicação. In: SARLET, Ingo Wolfgang; TIMM, Luciano Benetti (org.). Direitos fundamentais - Orçamento e reserva do possivel. 2. ed. Porto Alegre: Livraria do Advogado, 2010. 
LOPES, Ana Maria D’Ávila. A garantia do conteúdo essencial dos direitos fundamentais. Revista de Informação Legislativa, Brasília, DF, n. 164, p. 7-15, out./dez. 2004.

LOUREIRO, João Carlos. Direito à (protecção da) saúde. In: MIRANDA, Jorge (org.). Estudos em homenagem ao Professor Doutor Marcello Caetano no centenário de seu nascimento. Coimbra, Portugal: Coimbra Editora, 2006. v. 1.

LUPION, Ricardo. O direito fundamental à saúde e o princípio da impessoalidade. In: SARLET, Ingo Wolfgang; TIMM, Luciano Benetti (org.). Direitos fundamentais - Orçamento e "reserva do possível". 2. ed. Porto Alegre: Livraria do Advogado, 2010.

MAINGUÉ NETO, Wilson. O mandado de segurança e o direito à assistência à saúde. Curitiba: JM Editora, 2011.

MARQUES, Mário Reis. A dignidade humana como prius axiomático. In: ANDRADE, Manuel da Costa; ANTUNES, Maria João; SOUZA, Susana Aires de (org.). Estudos em homenagem ao Prof. Doutor Jorge de Figueiredo Dias. Stvdia Ivridica, Coimbra, Portugal, v. 4, n. 101, p. 541-566, 2010.

MIRANDA, Jorge. Manual de direito constitucional. 4. ed. Coimbra, Portugal: Coimbra Editora, 2008. NOVAIS, Jorge Reis. As restrições aos direitos fundamentais não expressamente autorizadas pela constituição. Coimbra, Portugal: Coimbra Editora, 2003.

NOVAIS, Jorge Reis. Direitos sociais - Teoria jurídica dos direitos sociais enquanto direitos fundamentais. Coimbra: Coimbra Editora: Wolters Kluwer, 2010.

NOVAK, Marko. Three models of balancing (in constitutional review). Ratio Juris, [S. l.], v. 23, i. 1, p. 101-112, mar. 2010.

PERLINGEIRO, Ricardo. Los cuidados de salud para los ancianos. Entre las limitaciones presupuestarias y el derecho a un mínimo existencial. Boletín Mejicano de Derecho Comparado, Ciudad de México, año XLVII, n. 140, p. 547-584, mayo/agosto 2014.

PERLINGEIRO, Ricardo. Novas perspectivas para a judicialização da saúde no Brasil. Scientia Ivridica, [S. l.], n. 333, p. 519-539, set./dez. 2013.

PERRY, Stephen R. Two models of legal principles. Iowa Law Review, [S. l.], n. 82, p. 787-819, [entre 1996 e 1997].

PHILIPPE, Xavier. Le contrôle de proportionnalité dans le jurisprudence constitutionnelle et administrative françaises. Paris: Economica: Presses Universitaires d'Aix-Marseille, 1990.

PINTO, Ilenia Massa. Contenuto minimo essenziale dei diritti costituzionali e concezione espansiva della costituzione. Diritto Pubblico, Milão, anno VII, n. 3, p. 1095-1117, 2001.

QUEIROZ, Cristina. Direitos fundamentais sociais - funções, âmbito, conteúdo, questões interpretativas e problemas de justiciabilidade. Coimbra, Portugal: Coimbra Editora, 2006.

SARLET, Ingo Wolfgang; FIGUEIREDO, Mariana Filchtiner. Reserva do possível, mínimo existencial e direito à saúde: algumas aproximações. In: SARLET, Ingo Wolfgang; TIMM, Luciano Benetti (org.). Direitos fundamentais, orçamento e reserva do possível. 2. ed. Porto Alegre: Livraria do Advogado, 2010. 
SARMENTO, Daniel. A proteção judicial dos direitos sociais: alguns parâmetros ético-jurídicos. In: SOUZA NETO, Cláudio Pereira; SARMENTO, Daniel (org.). Direitos sociais - Fundamentos, judicialização e direitos sociais em espécie. Rio de Janeiro: Lumen Juris, 2010.

SCHACHTER, Oscar. Dignity as a normative concept. American Journal of International Law, [S. l.], v. 77, i. 4, p. 848-854, Oct. 1983.

SCHWABE, Jürgen. Cinquenta anos de jurisprudência do Tribunal Constitucional Alemão. Tradução: HENNIG, Beatriz Hennig et al. Montevideo: Fundación Konrad-Adenauer, 2005.

SILVA, Virgílio Afonso da. Direitos fundamentais - Conteúdo essencial, restrições e eficácia. São Paulo: Malheiros, 2009.

SILVA, Virgílio Afonso da. O proporcional e o razoável. Revista dos Tribunais, São Paulo, v. 798, p. 23-50, 2002.

SOUZA NETO, Cláudio Pereira. A justiciabilidade dos direitos sociais: críticas e parâmetros. In: SOUZA NETO, Cláudio Pereira; SARMENTO, Daniel (org.). Direitos Sociais - Fundamentos, judicialização e direitos sociais em espécie. Rio de Janeiro: Lumen Juris, 2010.

TORRES, Ricardo Lobo. O mínimo existencial, os direitos sociais e os desafios de natureza orçamentária. In: SARLET, Ingo Wolfgang; TIMM, Luciano Benetti (org.). Direitos Fundamentais - orçamento e reserva do possível. 2. ed. Porto Alegre: Livraria do Advogado, 2010.

YOUNG, Katherine G. The minimum core of economic and social rights: a concept in search of content. Yale Journal of International Law, [S. l.], v. 33, p. 113-175, 2008. 